\title{
Knitting Tension During Weft-Knitting
}

\author{
By Noboru Aisaka, Tatsuya Kawakami and Tadashi Shindo, Members, TMSJ
}

Textile Research Institute of Japanese Government, Yokoyama, Kanagawa-ken

Based on Journal of the Textile Machinery Society of Japan, Transactions, Vol.22, No.3, T39--50 (1969)

\begin{abstract}
Knitting tension during weft-knitting is experimentally investigated with the aid of a model apparatus and a circular knitting machine. Although the knitting velocity in our experiment using the circular knitting machine was much lower than the ordinary velocity, it is possible to estimate real knitting tension from the results given in this article and in the light of those obtained by the experiment using the model apparatus.

(1) The larger the input yarn tension, the larger the knitting tension and the shorter the stitch length.

(2) Reductions in yarn tension and stitch length by robbing back are estimable from figures showing the relations between input yarn tension and knitting tension and between knitting tension and stitch length.

(3) The relation between knitting tension and the amount of work done by robbing back has nothing to do with knitting condition. The curve of that relation is conditioned by the properties of the yarn used.

(4) The larger the yarn and the higher its flexial rigidity, the larger the knitting tension. The lower the flexial rigidity of the yarn used, the lesser the effect of input yarn tension on knitting tension.
\end{abstract}

KEY WORDS: KNITTING, WEFT KNITTED FABRICS, WEFT KNITTING MACHINES, CIRCULAR KNITTING MACHINES, KNITTING TENSION, [YARN TENSION, ELONGATION, FRICTION, FLEXIAL RIGIDITY, STITCH CAMS, STITCH LENGTH, GAUGE, YARN.

\section{Introduction}

Knitting tension is an important quantity having a bearing on the stitch length of the knit fabric and therefore, on its quality and properties. A precise understanding of knitting tension is needed to fix yarn strength and decide what method to use for pre-processing the yarn.

In general, knitting tension $T_{k}$ during weft-knitting is a function of input yarn tension $T_{I}$; of yarn tesnsion $T_{o}$ at the exit of the knitting zone; of angle $\theta$ of the contact of the yarn with the knitting elements; and of frictional coefficient $\mu$ :

$$
T_{k}=f_{1}\left(T_{I}, T_{o}, \theta, \mu\right) \ldots \ldots \ldots \ldots \ldots \ldots \text { (1) }
$$

Knitting tension $T_{k}$ is a function of yarn tension $T_{o}$ because robbing back shows in weft-knitting. This effect of robbing back on knitting tension can be eliminated by controlling the movement of the needles in the region between the knitting point and the exit of the knitting zone, i.e., by lengthening the step of the stitch cam. This done, eq.(1) transforms into:

$$
T_{k}=f_{2}\left(T_{I}, \theta, \mu\right)
$$

With the needle distance (gauge) constant, angle $\theta$ is a function of the needle position in the knitting zone. When knitting tension is measured at the knitting point, angle takes a constant value. Knitting tension, then, is a function of input yarn tension and of the frictional coefficient of the yarn used.

2. Experiment with Model Apparatus.

2-1. Model Apparatus and Method of Experiment

The model apparatus (Fig.1) was experimentally constructed to simulate knitting on a desk. Sinkers $S_{1}$ and $S_{2}$ were fixed on panel $A$. Distance $G$ between $S_{1}$ and $S_{2}$ was variable. Needle $N$ was fixed on $\operatorname{rod} R$ which was supported by bracket $B$. Rod $R$ and needle $N$ were pushed up and down by cam $C$ which was rotated by a synchronous motor through a gear train.

When yarn $Y$ was being fed between needle $N$ and sinkers $S_{1}$ and $S_{2}$ while $\operatorname{rod} R$ was being pushed up, the yarn was bent in conformity to knitting action. The section (bc) of cam $C$ was so shaped that needle $N$ moved at a constant speed. Projection $D$ of cam $C$ was $3 \mathrm{~mm}$ high. 


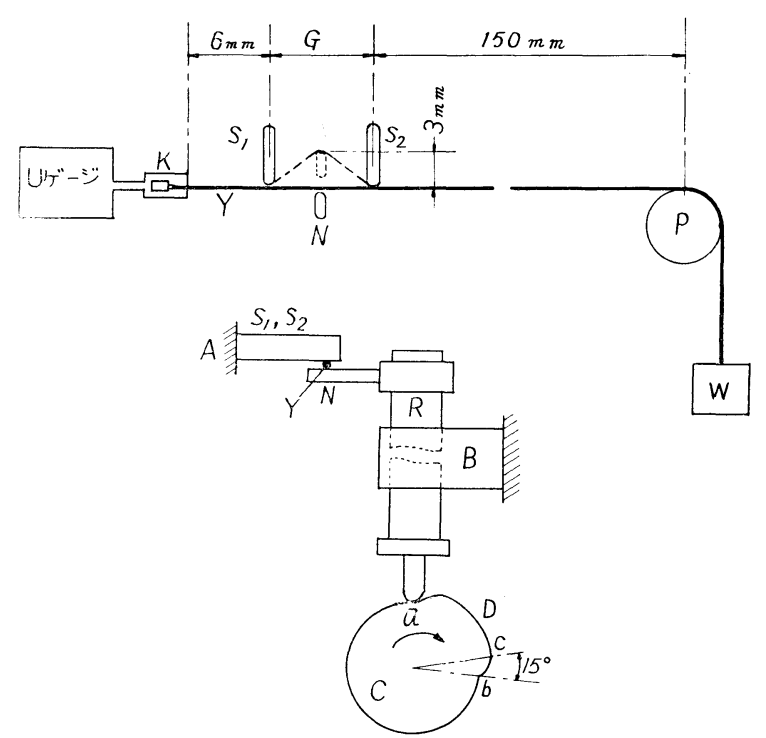

Fig. 1 Model apparatus for knitting

The circular cross sections of needle $N$ and sinkers $S_{1}$ and $S_{2}$ were all $0.8 \mathrm{~mm}$ in diameter.

Yarn $Y$ with load $W$ imposed on at one end was fed through pulley $P$ to the space between sinkers $S_{1}$ and $\mathrm{S}_{2}$ and needle $N$, and was gripped at the other end by clamp $K$ of unbonded-wire-strain-gauge $U$.

The variations in yarn tension by the simulated knitting were measured with a dynamic strain meter and recorded with Electro-Magnetic Oscillograph (YEW's "Photo corder') using a galvanometer of $-3 \mathrm{db}$ at $1000 \mathrm{c} / \mathrm{sec}$. At the time of each measurement, cam $C$ was placed at point (a) of contact with rod $R$, then the synchronous motor was set in motion. The first peak value in the record of each measurement was taken as knitting tension.

The yarns tested were worsted spun yarn 2/40's and stretched nylon yarn $110 \mathrm{~d} / 2$, whose properties are listed in Table 1 and marked with asterisks. The conditions under which the tests were made were:

Gauge $G(\mathrm{~mm}): 3,6,12$

Load $W(\mathrm{~g}): 2,6,10,15,20$

Knitting velocity $V(\mathrm{~cm} / \mathrm{sec}): 5,10,17,25,50$.

The knitting velocities were calculated from the records of variations in yarn tension at each measurement.

2-2. Results of Measurement Discussed

Fig. 2 shows the variations in yarn tension $T_{k}$ with input yarn tension $T_{I}$, i.e., load $W$, at a constant knitting velocity of $V=50 \mathrm{~cm} / \mathrm{sec}$ and a gauge of $G=3 \mathrm{~mm}$. Yarn tension $T_{k}$ of both yarns increased relatively to the increase in input yarn tension $T_{I}$. However, the relation between $T_{k}$ and $T_{I}$ was not linear but non-linear, and the degree of variations was high in a low range of the values of input yarn tension $T_{I}$.

Fig.3 shows the ratio $T_{k} / T_{I}$ plotted against input yarn

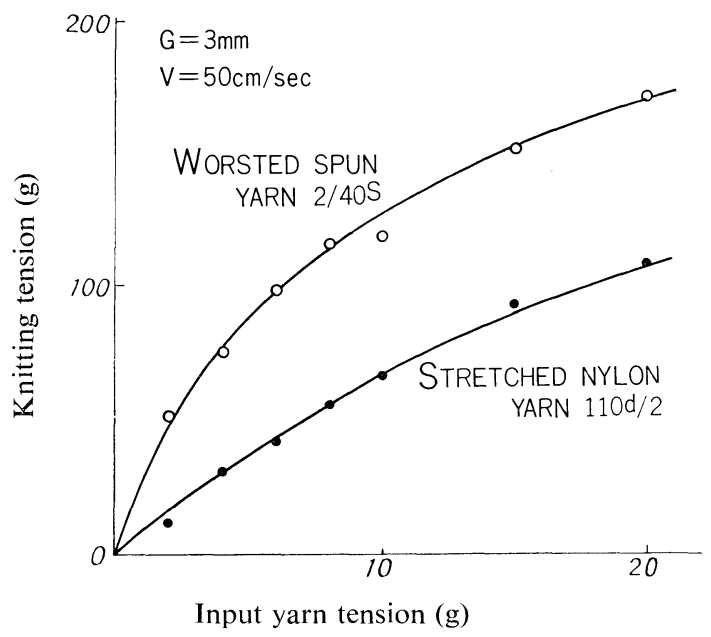

Fig. 2 Relation between input yarn tension and knitting tension (model apparatus)

tension $T_{I}$ from the results obtained from experiments in which gauge $G$ was varied and cam $C$ was manually rotated at a knitting velocity below $0.5 \mathrm{~cm} / \mathrm{sec}$. The ratio $T_{k} / T_{I}$ at $T_{I}=2 \mathrm{~g}$ on the worsted yarn was paticularly high and nearly constant at $T_{I} \geqq 10 \mathrm{~g}$. The same relation was noticed on the stretched nylon yarn, but the value at $T_{I}=2 \mathrm{~g}$ was not so high as in the worsted yarn.

The lower value of the ratio $T_{k} / T_{I}$ at $T_{I}=2 \mathrm{~g}$ on stretched nylon yarn was produced presumably because a good many crimps in the fibers remained and changed the condition of the surface of contact.

The relation between the ratio $T_{k} / T_{I}$ and input yarn tension $T_{I}$ is roughly the same, irrespective of gauge $G$, i.e., angle $\theta$ of wrap. Presumably, then, variations in the ratio to input yarn tension indicate variations in the coefficient of yarn friction. The conclusion is deducible, therefore, that, if we think of knitting tension as additional tension generated by friction, we should treat the coefficient of yarn friction as a function of yarn tension in a range of low input yarn tensions.

Comparing Figs. 2 and 3 shows that the ratio $T_{k} / T_{I}$ in Fig. 3 is higher on the stretched nylon yarn than on the worsted spun yarn, but that the reverse is the case in Fig. 2. This seems to suggest that knitting tension is influenced by knitting velocity.

In Fig.4, variations in knitting tension $T_{k}$ at gauge $G=$ $3 \mathrm{~mm}$ are plotted against knitting velocity, with input yarn tensions written alongside the curves. This figure shows that knitting tension increased as knitting velocity increased in a range under $V=10 \mathrm{~cm} / \mathrm{sec}$, but was almost constant in a higher speed-range on both yarns tested. Presumably, the increase of yarn tension by knitting is held in check by the inflow of the yarn. However, if yarn elongation exceeds yarn inflow in speed at a high knitting ve- 

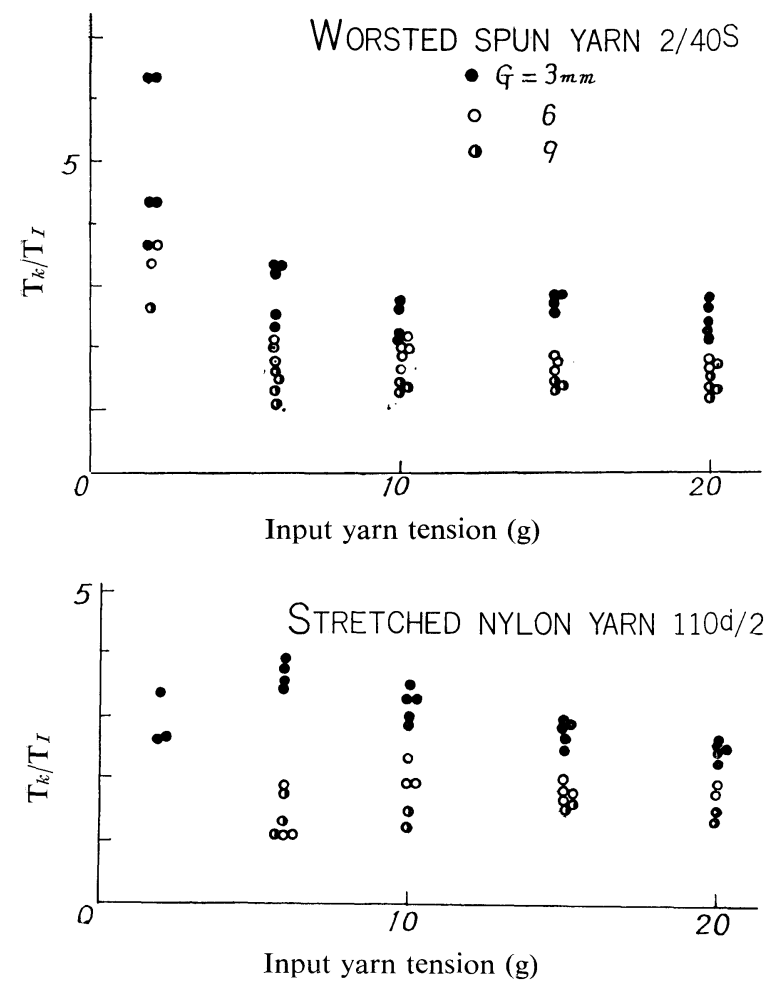

Fig. 3 Relation between input yarn tension $\mathrm{T}_{I}$ and ratio $\mathrm{T}_{k} / I \mathrm{~T}$

locity, then the restraint is weakened, thus permitting knitting tension to take a high value.

The difference between knitting tensions on the worsted spun yarn and the stretched nylon yarn presumably comes from the difference in elongation property between the two yarns. In a velocity range over $10 \mathrm{~cm} / \mathrm{sec}$, knitting tension is nearly constant. Therefore, in such a velocity range, the effect of the dragging tension of yarn on knitting tension is presumably slight, knitting tension being affected only by the frictional force and elongation property of the yarn.

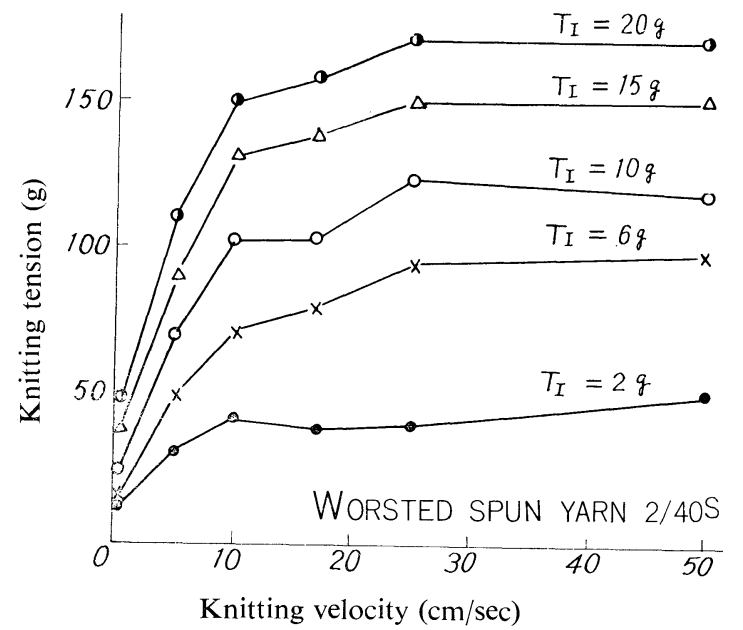

Journal of The Textile Machinery Society of Japan

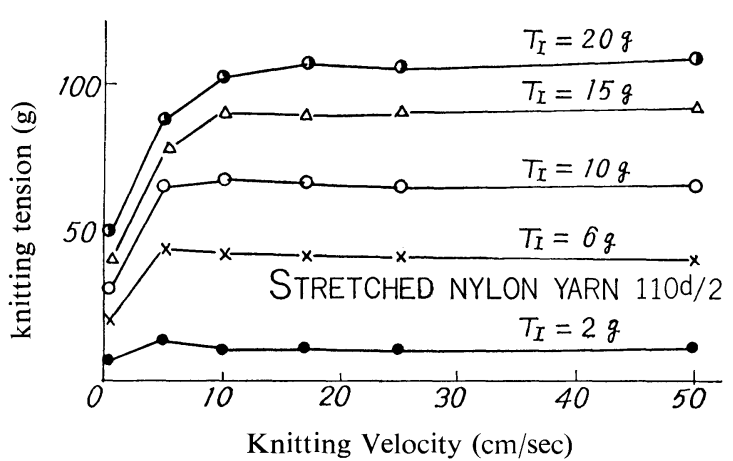

Fig. 4 Relation between Knitting Velocity and knitting tension

\section{Experiment with a Circular Knitting Machine.}

3-1. Knitting Machine Used and Method of Experiment. The knitting machine used was a circular open-top machine having a cylinder 20 inches in diameter and 12 needles per inch. The experiment was made at the rate of $3 \mathrm{rpm}$ of the machine (knitting velocity was about $8 \mathrm{~cm} / \mathrm{sec}$ ), using one yarn feeder. Input yarn tension was limited to a range of $1-13 \mathrm{~g}$ by a parallel disk-type tensioner pressed by a coil spring at a point on the route of yarn-feeding. Knitting tension was measured with a knitting-force-detector ${ }^{[1]}$ developed by the authors. The cams used were of 5 different shapes. Their steps were, respectively, in widths corresponding to 2, 3, 4 and 5 needles' distance as shown in Fig. 5. The regular stitch cam of this knitting machine was a CF-1 cam with a step of two-needles' distance.

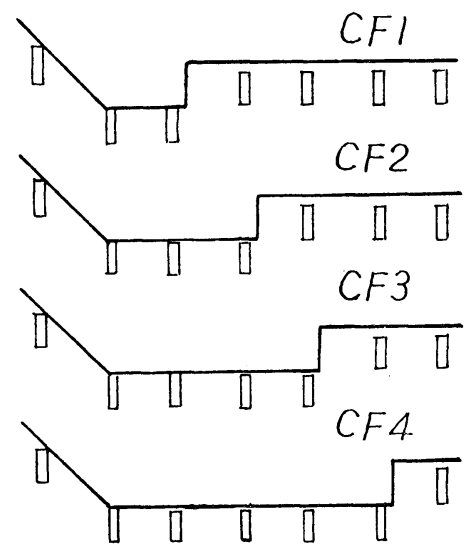

Fig. 5 Shapes of steps of stitch cams

\section{3-2. Results Discussed}

Fig.6 shows the relations between input yarn tension and knitting tension, and between knitting tension and stitch length obtained from experiments made at a constant cam setting of $\mathrm{h}=2.9 \mathrm{~mm}$, using the stitch cams shown in Fig.5. The curves expressing the relation between input yarn tension and knitting tension where the CF-4 stitch cam was 


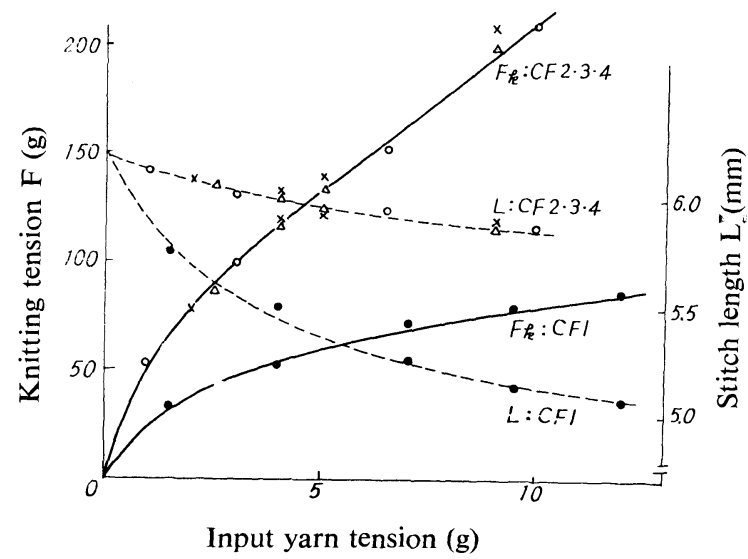

Fig. 6-1 Worsted spun yarn $2 / 40$ s

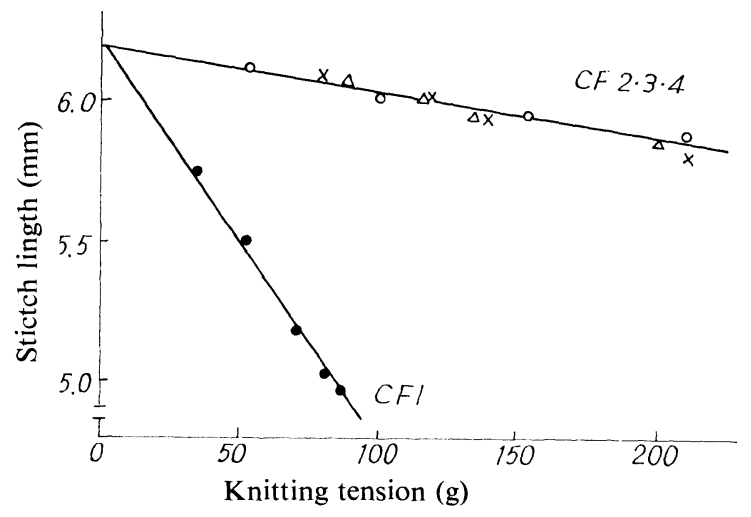

Fig. 6-2 Worsted spun yarn 2/40s

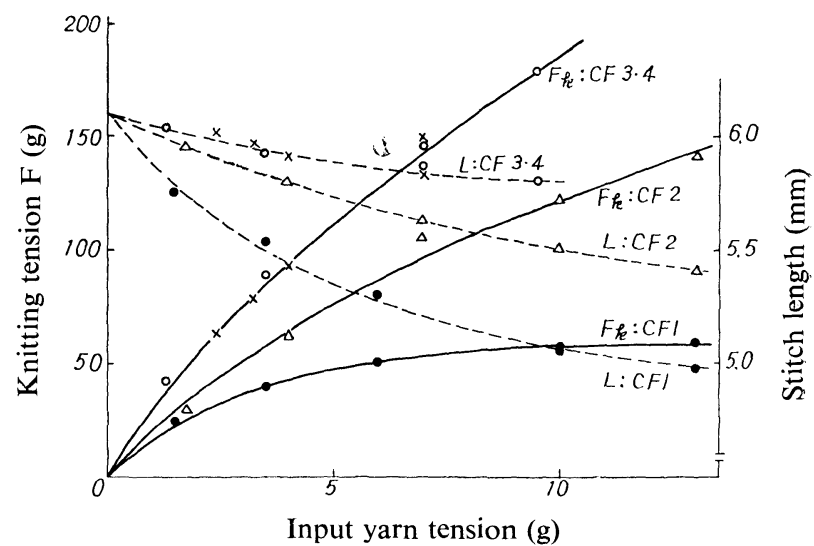

Fig. 6-3 Stretched nylon yarn 110/2d

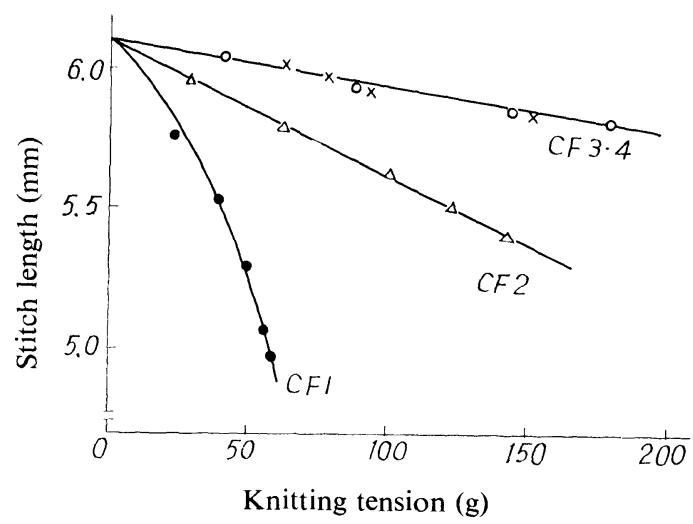

Fig. 6-4 Stretched nylon yarn 110/2d

Fig. 6 Relations between input yarn tension, and between knitting tension and stitch length (circular knitting machine)

used are all similar to that in Fig.2. Furthermore, the variations in stitch length in these experiments are a little smaller than those of input yarn tension.

These facts imply that robbing back did not show in knitting where the CF-4 cam was used. The effect of robbing back did show up in both knitting tension and stitch length where the regular CF-1 stitch cam was used.

Presumably, then, the difference between knitting tensions, $\mathrm{F}_{k 4}$ and $\mathrm{F}_{k 1}$ for cams CF-4 and CF-1, respectively, indicates a decreases in yarn tension by robbing back. Presumably, too, the difference between stitch lengths $L_{4}$ and $L_{1}$ for cams CF-4 and CF-1, respectively, at knitting tension $F_{k}$ indicates the decreases in the yarn length of the stitch by robbing back. These two decreases will be referred to hereinafter, respectively, as "robbing back tension $f_{r}$ " and "robbed back yarn length $l_{r}$." In other words:

$$
\begin{aligned}
& f_{r} \equiv F_{k 4}\left(T_{I}\right)-F_{k 0}\left(T_{I}\right) \ldots \ldots \ldots \ldots \\
& l_{r} \equiv L_{4}\left(F_{k 1}\left(T_{I}\right)\right)-L_{1}\left(F_{k 1}\left(T_{I}\right)\right) \ldots \ldots \ldots
\end{aligned}
$$

The product of $f_{r}$ and $l_{r}$ means the amount of work consumed by robbing back, or saved in the formation of the stitch, and will be referred to as "robbing back work $W_{r}$." In other words:

$$
W_{r} \equiv f_{r} \cdot l_{r}
$$

Eqs.(3), (4) and (5) can be solved for input yarn tension $T_{I}$, but robbing back shows up primarily because of knitting tension $F_{k}$. Therefore, it seems reasonable to investigate those values in terms of knitting tension $F_{k 1}$ in knitting with the regular stitch cam CF-1.

In Fig.7, robbing back tension $f_{r}$ and robbed back yarn length $l_{r}$ obtained from experiments made on the stretch nylon yarn with three different cam settings are plotted against knitting tension $F_{k 1}$.

Fig. 8 shows work $W_{r}$ by robbing back on both the worsted spun yarn and the stretched nylon yarn.

Fig.7 shows that both $f_{r}$ and $l_{r}$ increase as knitting tension does. The similar relation is found in the worsted spun yarn, although it is not illustrated by a figure in this article.

Fig. 8 shows that variations in $W_{r}$ differ according to the kind of yarn used, and that $W_{r}$ is indicated with the same curve, on the same kinds of yarns, regardless to the cam 


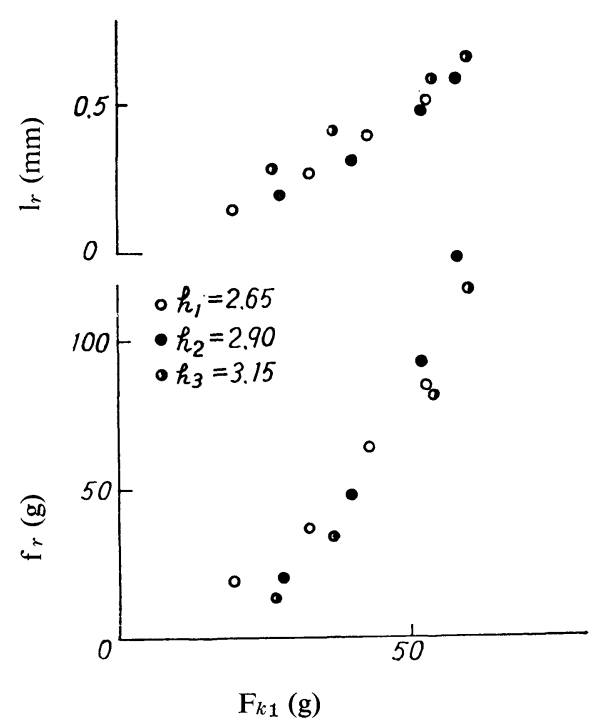

Fig. 7 Relations between knitting tension and robbing back tension and between knitting tension and robbed back yarn length

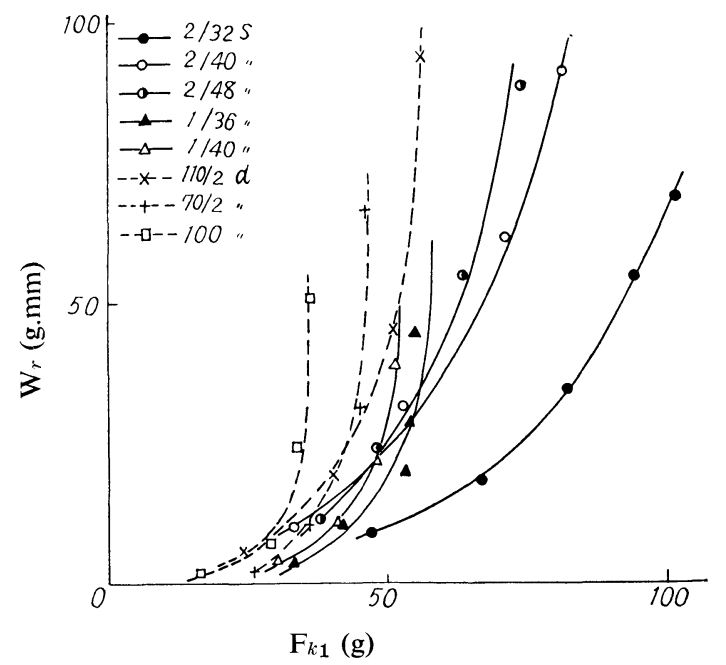

Fig. 8 Relation between knitting tension and robbing back work setting. This means that a curve showing the relation between knitting tension and the amount of work by robbing back represents the differ-ence between yarns in properties.

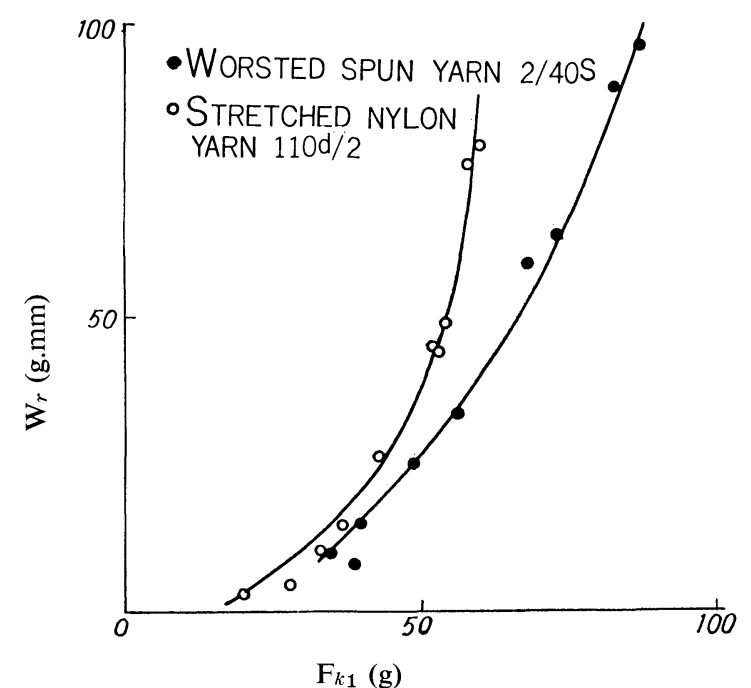

Fig. 9 Relation between knitting tension and robbing back work

Fig. 9 contains curves on several kinds of knitting yarns whose properties are given in Table 1 .

The amount of work by robbing back increases as kniting tension does. On stretched nylon yarn having a small elastic modulus $\mathrm{E}$, the amount of work by robbing back increases abruptly in some range of knitting tension. It increases gradually on spun-doubled yarn with a large elastic modulus. On spun-single yarn whose modulus $\mathrm{E}$ differs only slighly from that of spun-doubled yarn, variations in the amount of work by robbing back are similar in trend to those on stretched nylon yarn. Therefore, it is difficult to explain differences in variations in the amount of work by robbing back work in terms of differences in elastic modulus $\mathrm{E}$ or of frictional coefficient $\mu$ of the yarn.

In Fig.10, knitting tensions are plotted against yarn width calculated from the nominal counts or denier of the

Table 1 Properties of yarns used

\begin{tabular}{|c|c|c|c|c|c|c|}
\hline Sample & $\begin{array}{l}\text { Count or } \\
\text { Denier }\end{array}$ & $\begin{array}{l}\text { Strength } \\
\text { (g) }\end{array}$ & $\begin{array}{l}\text { Elongation } \\
(\%)\end{array}$ & $\begin{array}{l}\text { Elastic } \\
\text { modulus } \\
\qquad E\end{array}$ & $\begin{array}{c}\text { Frictionad } \\
\text { index } \\
T_{0} / T_{1} \\
\left(T_{I}=20 \mathrm{~g}\right)\end{array}$ & $\begin{array}{c}\text { Flexial } \\
\text { rigidity } \\
G \underset{\left(\times 10^{-3}\right.}{\left.\mathrm{g.cm}^{2}\right)}\end{array}$ \\
\hline Worsted spun yarn & $1 / 40 \mathrm{~s}$ & 362 & 32.8 & 5580 & 1.65 & 4.78 \\
\hline $\begin{array}{l}\text { Wool and Acryl } \\
\text { mixed spun yarn }\end{array}$ & $1 / 36 s$ & 364 & 23.8 & 6100 & 1.69 & 5.76 \\
\hline "I & $2 / 48 \mathrm{~s}$ & 414 & 30.0 & 5870 & 1.74 & 8.56 \\
\hline Worsted spun yarn*) & $2 / 40 \mathrm{~s}$ & 342 & 24.0 & 7620 & 1.66 & 8.68 \\
\hline II & $2 / 32 s$ & 376 & 21.0 & 6920 & 1.78 & 12.4 \\
\hline Stretched nylon yarn & $100 \mathrm{~d}$ & 520 & 38.0 & 1550 & 1.65 & 1.47 \\
\hline "I & $70 / 2 d$ & 428 & 22.4 & 1880 & 1.69 & 1.35 \\
\hline$*)$ & $110 / 2 d$ & 876 & 38.8 & 2580 & 1.70 & 2.71 \\
\hline
\end{tabular}




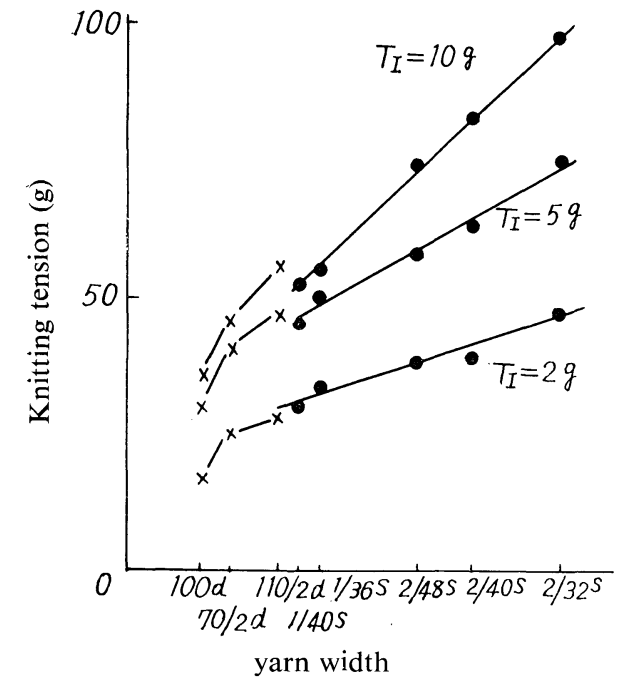

Fig. 10 Relation between yarn Width and knitting tension

yarns. It seems from this figure that knitting tension is influenced by some properties related to yarn width.

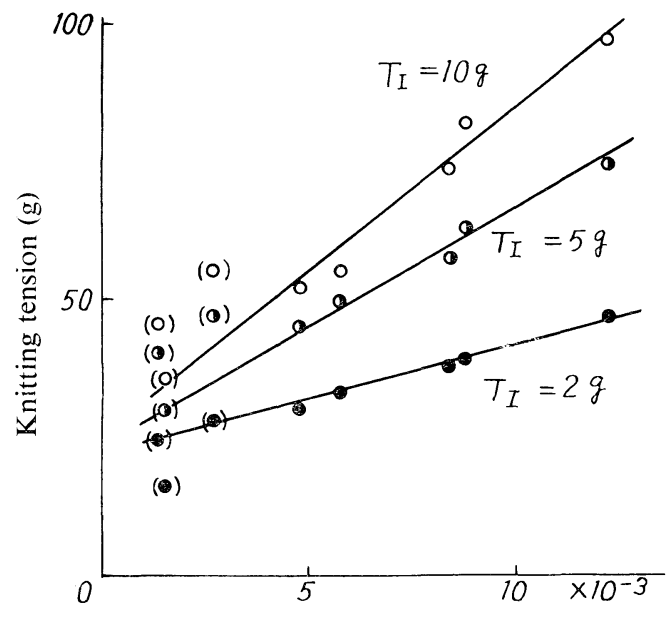

Flexial rigidity of yarn (g.cm)

Fig. 11 Relation between flexial rigidity of yarn and knitting tension

In Fig. 11, knitting tensions are plotted against the flexial rigidity of yarn measured by the ring method. ${ }^{[2],[3]}$ The notations in parentheses show data on stretched nylon yarns and others on the spun yarns.

Presumably, variations in knitting tension and in stitch length are influenced by the flexial rigidity of the yarn used. In other words, variations in a small range of yarn tension relate mainly to yarn bending, or to the yarn movement if yarn tension is in a large range. Therefore, it is necessary to look further into such matters as the angle of wrap in the knitting zone, state of yarn-bending by the knitting elements and the proportions of the elastic and plastic portions in the cross section of the yarn bent.

\section{Conclusions.}

(1) The larger the input yarn tension, the larger the knitting tension. Variations in knitting tensions are influenced by the properties of the yarn used, especially by its frictional and elongational properties.

(2) The larger the knitting tension, the shorter the stitch length.

(3) The coefficient of yarn friction should be treated as a function of yarn tension if knitting tension is thought of as additional tension generated by friction.

(4) Comparing the results of experiments made with the regular stitch cam and the results of experiments made with a stitch cam whose step is too wide for robbing back to show up, we find that decreases in yarn tension and stitch length by robbing back are estimable from figures showing the relations between input yarn tension and knitting tension and between knitting tension and stitch length.

(5) The amount of work done by robbing back is defined by the product of the decreases in yarn tension and in stitch length. The relation between knitting tension and the amount of work done by robbing back has nothing to do with knitting condition. The curve of that relation is conditioned by the properties of the yarn used.

(6) The larger the yarn width and the flexial rigidity of the yarn used, the larger the knitting tension. The relation between knitting tension and the flexial rigidity of yarn is almost linear. The lower the flexial rigidity of the yarn used, the lesser the effect of input yarn tension on knitting tension.

The authors are much indebted to Prof. S. Ishikawa of the Tokyo Institute of Technology for valuable suggestions on the experiments.

\section{Literature cited}

[1] Aisaka, Kawakami Shindo; J. Fib. Sci. Tech. Japan, 24, 70 (1968)

[2] Kawakami, Ikeda; Bull. Text. Res. Inst. Japan, No.32, 14 (1955)

[3] Shimizu Ikemura Tabata Uno; J. Text. Mach. Soc. Japan, 19, T301 (1966) 